\title{
PENERAPAN ALAT PEMBELAH BUAH PINANG MANUAL YANG ERGONOMIS DI DESA KAYU RAJA-KABUPATEN INHIL-RIAU
}

\author{
Anwardi $^{1)}$, Nofirza ${ }^{2)}$, Harpito $^{3)}$ \\ 1,2,3 Program Studi Teknik Industri, Fakultas Sains dan Teknologi, Universitas Islam Negeri Sultan Syarif Kasim Riau \\ Jl. HR. Soebrantas Km 15 No. 55 Pekanbaru \\ * Penulis Korespodensi : anwradi@uin-suska.ac.id
}

\begin{abstract}
Abstrak
Untuk dapat menjual buah pinang kepada pengumpul, salah satu proses pengolahan yang harus dilalui adalah proses pembelahan. Proses pembelahan dilakukan dengan menggunakan alat pembelah. Jenis alat pembelah yang digunakan saat ini belum memenuhi kriteria ergonomi yang menyebabkan pekerja merasakan keluhan kelelahan dan keluhan muskuloskeletal setalah melakukan aktivitas pembelahan buah pinang. Kemudian pekerja juga sering mengalami kecelakaan kerja berupa luka pada tangan. Untuk itu dilakukan rancangan ulang alat pembelah pinang yang dapat meminimalisir tingkat kecelakaan kerja, menurunkan keluhan kelelahan dan muskuloskeletal serta meningkatkan produktivitas kerja melalui pendekatan ergonomi. Hasil rancangan memilki dimensi tinggi tempat duduk $37 \mathrm{~cm}$, lebar $54 \mathrm{~cm}$, diameter pegangan pisau 2 $\mathrm{cm}$, panjang pegangan peniumbuk $21 \mathrm{~cm}$, tinggi penumbuk $35 \mathrm{~cm}$. Sementara teknik kerja pisau pembelah dalam keadaan diam. implementasi menunjukkan bahwa terjadi penurunan keluhan kelelahan sebesar $24,12 \%$, keluhan muskuloskeletal $15,83 \%$ dan terjadi peningkatan produktivitas sebesar $12,76 \%$.
\end{abstract}

Kata Kunci: Ergonomis, Kecelakaan Kerja, Kelelahan, Produktivitas

\begin{abstract}
To be able to sell betel nut to collectors, one of the processing processes that must be passed is division. The cleavage process is carried out using a splitting device. The type of equipment currently used does not meet the ergonomic criteria which causes workers to feel complaints of fatigue and musculoskeletal complaints after doing areca fruit cleavage activities. Then workers also often experience work accidents in the form of injuries to the hand. For this reason, a re-design of areca cutters is done to minimize work accident rates, reduce fatigue and musculoskeletal complaints and increase work productivity. The results of the implementation showed that there was a decrease in fatigue complaints by $24.12 \%$, musculoskeletal complaints $15.83 \%$ and an increase in productivity of $12.76 \%$
\end{abstract}

Keywords: Ergonomics, Work Accidents, Fatigue, Productivit 


\section{Pendahuluan}

Suatu proses kerja merupakan suatu sistem kerja yang saling mendukung satu sama lain. Sistem kerja yang tidak ergonomis dalam suatu kegitan kerja seringkali tidak mendapat perhatian dari orang-orang yang berwenang, baik itu atasan maupun pekerja itu sendiri. Sebagai contoh cara, sikap dan posisi kerja pada proses pembelahan buah pinang di Desa Kayu Raja Kec. KeritangIndragiri Hilir.

Kabupaten Indragiri Hilir (Inhil) merupakan salah satu dareah penghasil buah pinang yang terletak dipropinsi Riau. Jumlah produksi buah pinang di Inhil berkembang secara cepat dan di ekspor ke luar negeri, seperti India, Sri Lanka, dan Pakistan. Di Negara ini, buah pinang merupakan suguhan makanan kecil yang cukup diminati, buah pinang diiris kecil dan disangrai, kemudian dikemas dalam kantong plastik atau kaleng seperti halnya kacang yang dikemas dalam plastik. Industri makanan dan tekstil juga mulai melirik buah pinang sebagai bahan pewarana, karna sari biji pinang yang berwarna merah anggur berpotensi sebagai pewarna kain dan makanan. Penggunaan warna merah yang berasal dari biji ini sekarang sangat dianjurkan oleh Organisasi Kesehatan Dunia (WHO) dan badan-badan kesehatan lainnya. Sebab, warna merah buatan bersifat karsinogenik atau menyebabkan kanker (Kompas.com, 2010).

Desa Kayu Raja merupakan suatu desa yang berada di Kec. Keritang - Indragiri Hilir. Desa tersebut merupakan salah satu desa yang melakukan proses pembelahan buah pinang dengan alat yang masih sederhana, segi ergonomi dan penerapan mengenai kesehatan kerja belum diterapkan. Hal ini dapat dilihat dari sikap kerja yang tidak alamiah, seperti sikap kerja (duduk) dan penggunaan desain kursi dalam bekerja, karena sikap badan yang tidak benar dalam melakukan pekerjaan dan lain-lain yang kesemuanya menimbulkan kelelahan fisik dan gangguan kesehatan bahkan lambat laun dapat terjadi perubahan fisik tubuh pekerja atau kecacatan ( Suma'mur, 2009).

Proses pembelahan buah pinang di Kec. Keritang - Inhil saat ini masih dilakukan dengan cara manual dan mebutuhkan tenaga masnusia, meskipun mesin pengupas dan pembelah telah banyak di jual, namun pekerja tetap memilih menggunakan alat manual dengan alasan faktor harga. Harga mesin pembelah buah pinang yang mencapai Rp. 25.000.000/Unit bagi pekerja pinang termasuk sangat mahal. Untuk itu para pekerja buah pinang masih bertahan menggunakan alat pembelah yang ada saat ini, meskipun dari aspek ergonomis dan kesehatan tidak memenuhi kaidah-kaidah yang dibenarkan. Adapun gambar alat pembelah pinang yang digunakan masyarakat Desa Kayu Raja Kec. Keritang - Inhil adalah sebagai berikut:
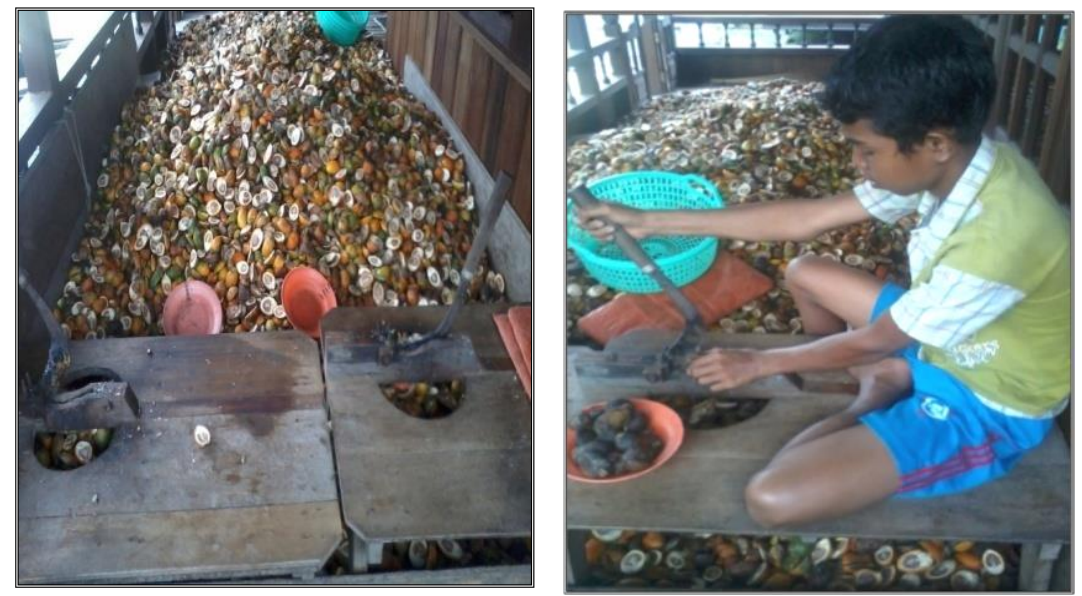

Gambar 1. Alat Pembelah Buah Pinang 
Para pekerja buah pinang melakukan pekerjaan yang kurang nyaman seperti, mengambil buah pinang yang akan dibelah, meletakkan dialat pembelah, duduk tanpa sandaran sehingga pekerja buah pinang cepat mengalami kelelahan juga cenderung lebih sering mengalami sakit akibat kerja, seperti menderita sakit punggung bagian bawah, bahu, leher dan tangan. Menurut Anies (2014) sikap tubuh serta aktivitas tertentu terhadap alat kerja, berpotensi menimbulkan suatu gangguan kesehatan, bahkan penyakit.

Hasil survei dengan menggunakan kuesioner Nordic Body Map terhadap 10 pekerja buah pinang setelah bekerja diperoleh $60 \%$ pekerja mengeluh rasa sakit pada punggung, $80 \%$ mengeluh sakit pada pinggang, $90 \%$ mengeluh sakit pada bokong, $80 \%$ mengeluh pada bagian pantat, $40 \%$ mengeluh sakit pada bahu, lengan dan beberapa anggota tubuh bagian atas dan bawah.

Berdasarkan kondisi tersebut, maka perlu dilakukan perbaikan metode kerja pada pekerja pinang melalui implementasi hasil desain alat pembelah buah pinang ergonomis pada pekerja buah pinang di Desa Kayu Raja Kec. Keritang - Inhil". Hasil penelitian Susana (2016) menyatakan redesain stasiun kerja berupa rancangan secara tradisional dapat menurunkan keluhan muskuloskeletal sebesar $26,7 \%$.

Alat pembelah buah pinang berperan penting dalam proses pengolahan buah pinang. Peningkatan kemampuan belah dengan menggunakan alat pembelah buah pinang saat ini cukup membantu pekerja pinang jika ditinjau dari sisi produktivitas, namun disisi lain pekerja sering merasakan keluhan akibat rasa sakit pada beberapa bagian tubuh pekerja, seperti pantat, kesemutan bagian kaki, kecelakaan tangan pada pekerja akibat bentuk, ukuran dan cara kerja alat yang tidak tepat atau ergonomis. Untuk itu perlu penerapan teknologi sederhana dan cara kerja yang baik dalam menunjang proses pengolahan buah pinang, khususnya pada proses pembelahan buah pinang yang ada di Desa Kayu Raja.

Adapun tujuan dari kegiatan ini adalah:

1. Mengetahui tingkat resiko kecelakaan kerja pada pekerja dengan menggunakan alat pembelah buah pinang hasil rancangan.

2. Mengetahui penurunan keluhan muskuloskeletal dalam menggunakan alat pembelah buah pinang hasil rancangan .

3. Mengetahui penigkatan produktivitas kerja dalam menggunakan alat pembelah buah pinang hasil rancangan.

\section{Metode}

Berdasarkan hasil survey dilapangan bahwa alat pembelah yang digunakan saat ini sangat memungkinkan terjadinya kecelakaan kerja pada tangan pekerja yang disebabkan oleh cara kerja dan desain piasu pembelah yang tidak ergonomis, sehingga perlu dilakukan perbaikan cara kerja dan desain alat pembelah yang lebih aman bagi pekerja. Kemudian, umumnya pekerja dalam melakukan aktivitas membelah buah pinang berada pada postur tubuh yang beresiko, seperti membungkuk, menunduk dan postur tidak alamiah lainnya, hal tersebut terjadi karena alat yang digunakan tidak memadai yang berpotensi menimbulkan keluhan kelelahan dan muskuloskeletal. Selain dari faktor keluhan kelelahan dan muskuloskeletal, tentunya hasil produktivitas harus dipertimbangkan dalam melakukan rancangan alat pembelah buah pinang. Desain alat yang sesuai 
dengan postur tubuh dapat meningkatkan produktivitas kerja seseorang dalam beraktivitas. Sebagaimana dalam penelitian (Daryanto, 2016), Redesain rakel dan pemberian peregangan aktif meningkatkan produktivitas kerja sebesar $45,5 \%$ pada pekerja sablon kain. Setiap desain suatu peralatan atau produk dimana manusia harus ada di sana sebagai operator maupun pemakai produk tersebut, maka faktor kemampuan, kebolehan dan keterbatasan manusia harus ditempatkan sebagai fokus utama (Sutalaksana, 2000).

Sasaran dalam kegiatan program pengabdian kepada masyarakt ini adalah para pekerja yang ada di Desa Kayu Raja yang masih menggunakan alat pembelah dengan berbagai kekurangan. Pekerja buah pinang diharapkan mampu menggunakan dan memberikan pengetahuan kepada pekerja lainnya yang ada di Kabupaten Inhil, sehingga kegiatan ini bermanfaat bagi masyarakat luas.

Program pengabdian kepada masyarakat dilaksanakan dengan terlebih dahulu melakukan upaya sosialisasi tentang kesehatan dan keselamat kerja kepada pekerja pinang yang ada di Desa Kayu Raja akibat sikap kerja dan penggunaan peralatan yang tidak ergonomis. Sosialisasi ini melibatkan sekitar 20 pekerja yang dapat mewakili pekerja pinang yang ada di Desa Kayu Raja maupu pekerja desa lain.

Alat pembelah buah pinang hasil rancangan peneliti sebelumnya kemudian diterapkan pada proses pengolahan buah pinang, terutama pada proses pembelahaan.

Penggunaan peralatan baru kepada para pekerja tentu tidak akan langsung bisa dengan baik, sehingga diperlukan waktu pelatihan agar pekerja terbiasa melakukan kegiatan pembelahan. Pelatihan juga disisipi pelajaran tentang ilmu fisiologi, khususnya bagaimana bekerja agar tetap bugar, tidak sakit, tidak lelah serta selalu senang.

Setelah dilakukan pelatihan, selanjutnya adalah penerapan alat pembelah buah pinang hasil rancangan kepada pekerja yang sebelumnya telah dilatih. Untuk dapat melakukan evaluasi terhadap hasilyang dicapai, maka terdapat beberapa instumen yang digunakan untuk mendapatkan data, adapun peralatan yang digunakan antara lain:

a. Koesioner

b. Formulir produktivitas kerja digunakan untuk mengambil data kemampuan belah.

c. Stopwatch

d. Software SPSS dan Microsoft Excel

e. Formulir biodata pekerja digunakan untuk mengambil data pekerja yaitu usia dan masa kerja.

f. Camera Digital yang berfungsi untuk mengambil dokumentasi seperti keadaan fasilitas kerja yang digunakan dan postur tubuh ketika bekerja untuk kemudian dilakukan evaluasi.

Adapun indikator capaian tujuan dalam kegitan pengabdian kepada masyarakt ini adalah sebagai berikut:

1. Alat pembelah buat pinang hasil rancangan dapat meminimalisir terjadinya kecelakaan kerja;

2. Alat pembelah buah pinang hasil rancangan dapat menurunkan keluhan kelelahan sebesar $20 \%$ dan musculoskeletal $15 \%$

3. Alat pembelah buah pinang hasil rancangan dapat meningkatkan produktivitas kerja sebesar $10 \%$.

Tolak ukur yang dipergunakan dalam kegiatan ini dengan menggunakan hasil pengukuran dengan menggunakan instrument yang telah ditetapkan. Untuk mengetahui keberhasilan program kegiatan yang dilakukan dengan menggunakan perhitungan produktivitas dan uji statistik. Analisis 
data dibagi dalam tiga bagian yaitu analisis deskriptif, uji normalitas dan uji beda dengan tujuan untuk mengetahui perbedaan penurunan kelelahan dan keluhan muskuloskeletal, peningkatan produktivitas kerja.

\section{Hasil dan Pembahasan Profil Desa Kayu Raja}

Desa Kayu Raja merupakan salah satu desa yang ada di Kecamatan Keritang Kabupaten Indragiri Hilir (Inhil) yang baru mekar pada tahun 2011 berdasrkan peraturan Daerah Kabupaten Indragiri Hilir No. 6 Tahun 2011. Pada awalnya Desa Kayu Raja berada pada naungan Kelurahan Kotabaru Reteh dengan ibu kota Sungai Gergaji. Seiring dengan perkembangan jumlah penduduk, maka Kelurahan Kotabaru Reteh dipecah menjadi dua yaitu Kelurahan Kota Baru Reteh dan Desa Kayu Raja. Jumlah penduduk Desa Kayu Raja sebanyak 1895 jiwa dengan rasio 902 berjenis kelamin laki-laki dan 993 berjenis kelamin perempuan serta terdiri dari 475 Rumah Tangga (BPS. Inhil 2016).

Sebagian besar pekerjaan masyarakat Desa Kayu Raja adalah petani dan berkebun. Sumber penghasilan utama masyarakat Desa Kayu Raja adalah kelapa sawit, kelapa lokal, padi dan pinang. Berdasarkan data dari kecamatan keritang bahwa pinang berada pada posisi ketiga dari komoditi lainnya sebagaimana pada gambar berikut.

\section{Proses Sosialisasi}

Tahap pertama yang dilakukan dalam program pengabdian kepada masyarakat adalah melakukan sosialisasi tentang kesehatan dan keselamatan kerja kepada pekerja buah pinang yang ada di Desa Kayu Raja. Materi yang disampaikan adalah terkait dengan hubungan peralatan atau fasilitas yang digunakan dalam mengolah buah pinang terhadap keselamatan dan kesehatan pekrja. Peralatan yang digunakan oleh pekerja saat ini belum mempertimbangkan keselamatan dan kesehatan para pekerja buah pinang dan belum memenuhi kaedah-kaedah ergonomi yang sering disebut juga sebagai "Human Factors".

Penerapan ergonomi pada umumnya merupakan aktivitas rancang bangun (disain) ataupun rancang ulang (re-disain). Untuk meningkatkan kemampuan tubuh manusia, maka beberapa hal di sekitar lingkungan alam manusia misal peralatan, lingkungan fisik, posisi gerak (kerja) perlu direvisi atau dimodifikasi atau didesain ulang disesuaikan dengan kemampuan tubuh manusia. Begitu juga dengan alat pembelah buah pinang yang digunakan oleh pekerja pinang yang ada di Desa Kayu Raja saat ini, sering melukai tangan pekerja, posisi kerja membungkuk dengan frekuensi pengulangan yang tinggi.

Setelah melakukan sosialisasi kepada masyarakat tentang bahaya yang akan ditimbulkan oleh alat pembelah buah pinang saat ini, baik bahaya jangka pendek maupun jangka panjang berdasarkan teori ergonomi, maka tahap selanjutnya mengajak pekerja untuk menerapkan alat hasil rancangan alat yang ergonomis. Berikut adalah gambar proses sosialisasi di Desa Kayu Raja bersama perangkat Desa dan masyarakat pekerja pinang. 

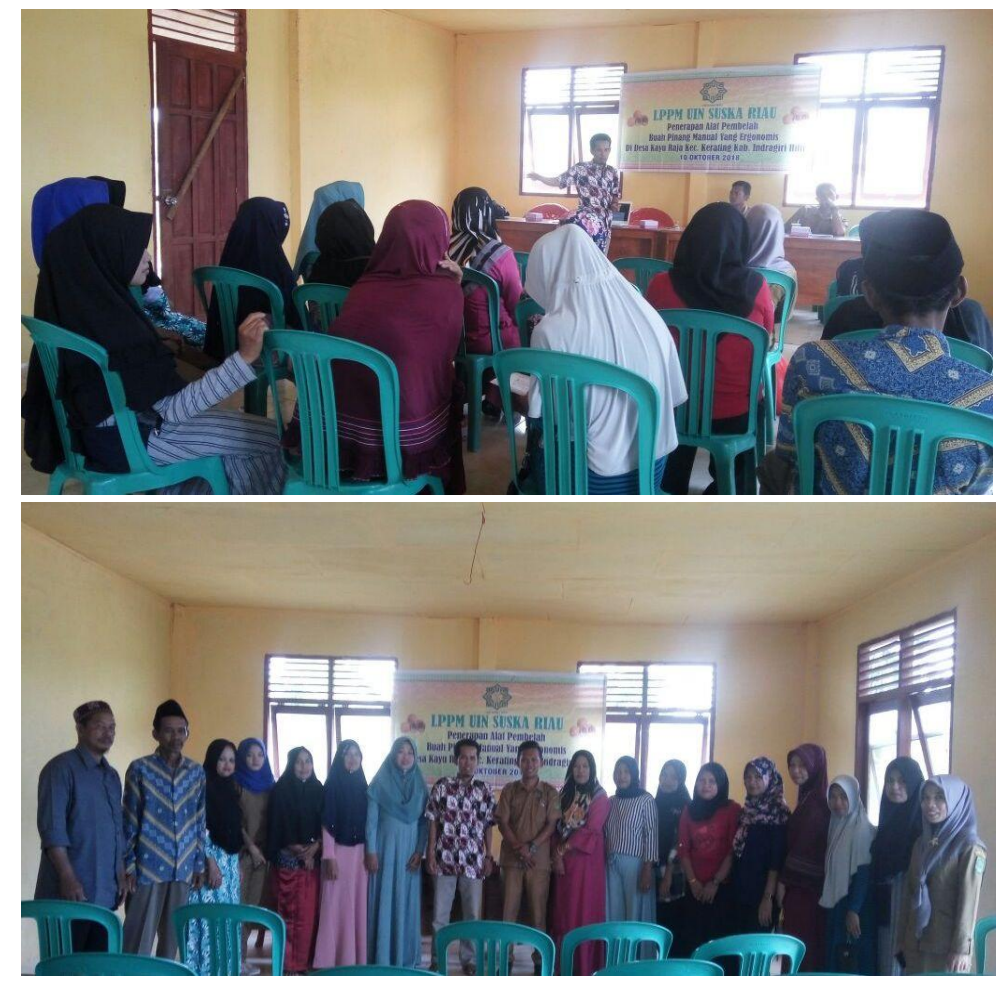

Gambar 2. Foto Bersama Perangkat Desa dan Pekerja Pinang

\section{Pelatihan Bagi Para Operator/Pekerja}

Langkah selanjutnya adalah proses pelatihan dalam menggunakan alat pembelah buah pinang hasil rancangan. Tujuan dari pelatihan ini untuk mengenalkan dan membiasakan kepada para pekerja buah pinang dalam penggunaan alat hasil rancangan. Diperlukan lebih kurang sehari untuk mengenalkan agar para petani terbiasa dan mampu menggunakan alat hasil rancangan dengan baik. Pelatihan juga diselingi dengan pelajaran tentang ilmu fisiologi agar dalam melakukan aktivitas kerja kondisi tubuh tetap bugar, tidak sakit, tidak cepat lelah serta senantiasa senang dan bahagia.

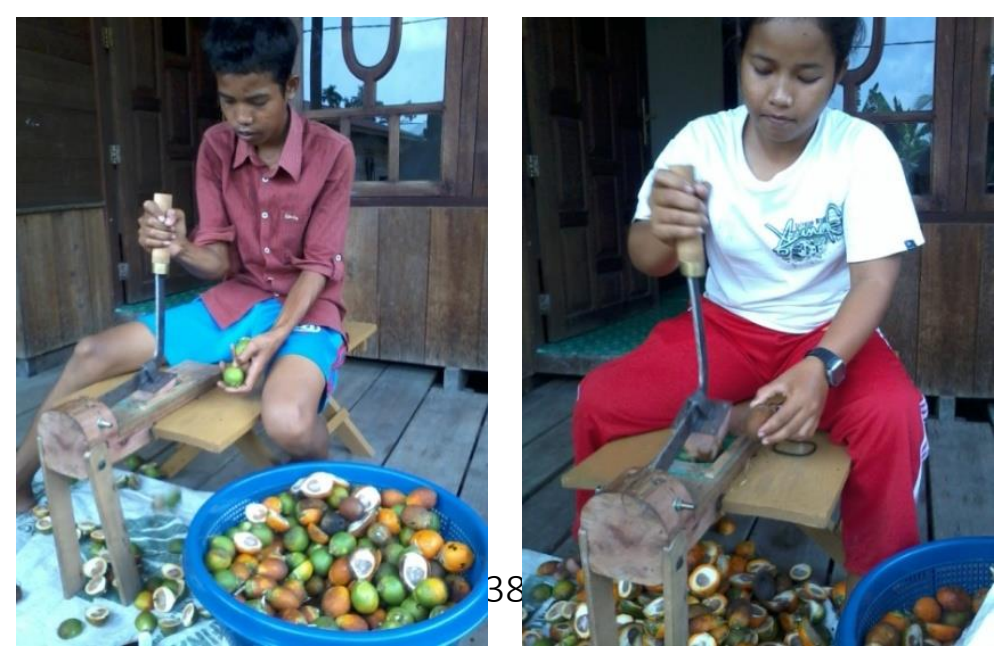




\section{Gambar 3. Proses Pelatihan}

\section{Penerpaan Alat Pembelah Buah Pinang Hasil Rancangan}

Sebagai luaran dari pelaksanaan program pengabdian kepada masyarakat ini adalah sebagai berikut:

1. Mengaplikasikan Teknologi Tepat Guna dengan menerapkan teknologi yang senantiasa mempertimbangkan keriteri yaitu mudah dalam membuatnya, biaya murah, ramah lingkungan, hemat energi dan tidak merugikan kesehatan. Ciri tersebut mampu terakomodasi oleh hasil rancangan alat pembelah buah pinang ergonomis.
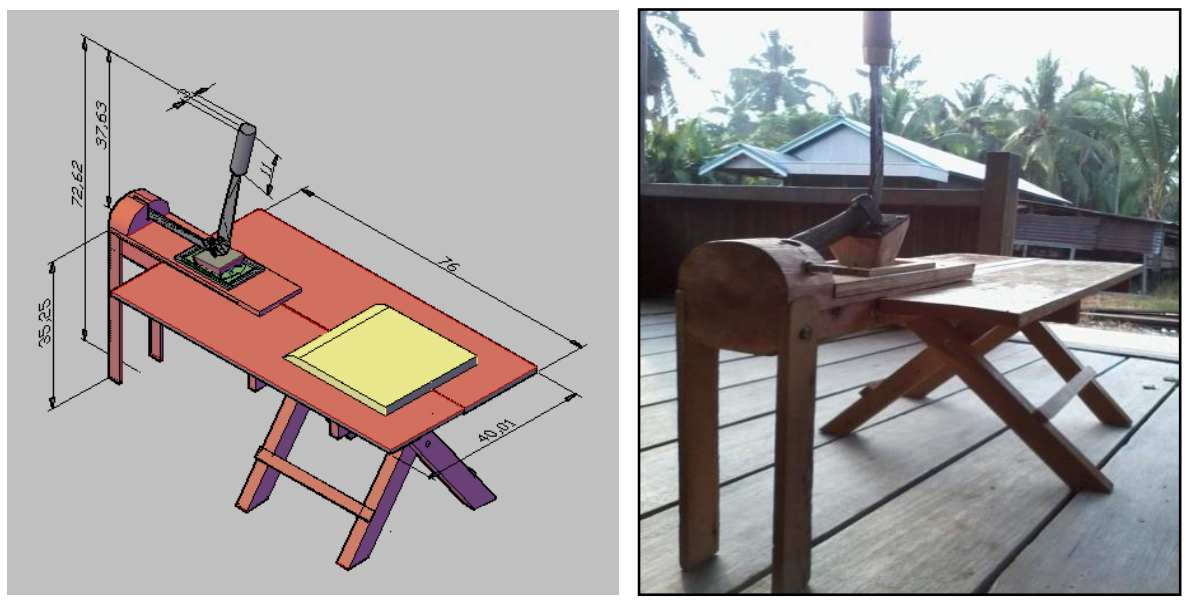

Gambar 4. Pembelah Buah Pinang Ergonomis

2. Implementasi metode ergonomis dalam aktivitas pengolahan buah pinang, khususnya proses pembelahan, dibutuhkan pemahaman mengapa badan terasa sakit setelah melakukan aktivitas kerja dan terkadang muncul kehilangan motivasi. Program Pengabdian Kepada Masyarakat ini tidak hanya memberi peralatan, akan tetapi juga memberikan ilmu dan teori tentang cara-cara bekerja sehat dan produktiv. Berikut gambar penerapan alat pembelah buah pinang hasil rancangan.
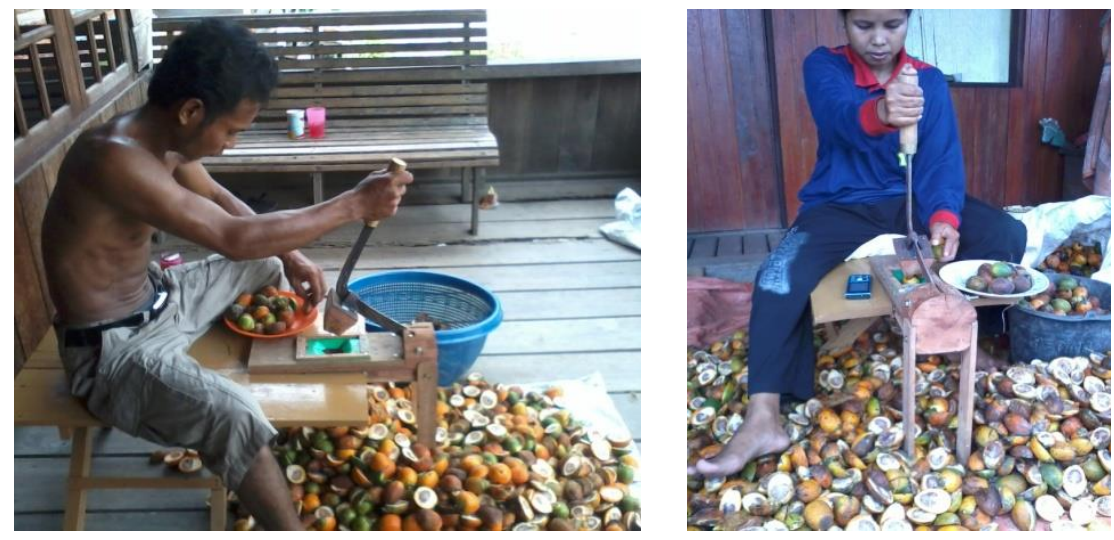


\section{Gambar 5. Penerapan Alat Pembelah Buah Pinang Ergonomis}

Alat pembelah buah pinang ergonomis terbuat dari bahan kayu, besi dan plastik yang terdiri dari rangka dan tempat duduk, mata pisau, alat penumbuk buah pinang, dudukan penumbuk pinang, penjempit atau tempat meletakkan buah pinang. antara penumbuk buah pinang dengan tempat duduk disambung dengan menggunakan baut. Sementara pisau pembelah diletakkan di bawah penjempit buah pinang. Secara teknis penggunaannya dilakukan dengan menarik penumbuk kerah operator, sehingga pinang mengalami tekanan dari atas dan terbelah saat masuk ke dalam lubang yang di dalamnya terdapat pisau. Alat ini mampu mengurangi resiko terjadinya kecelakaan terhadap pekerja. Selain itu alat ini juga dapat di lipat sehingga mempermudah dalam proses penyimpanan dan pemindahan.

Untuk mengetahui keberhasilan suatu rancangan diperlukan pengujian dan perbandingan output yang dihasilkan. Sebelum melakukan perhitungan, langkah pertama yang dilakukan adalah melakukan uji normalitas. Uji normalitas yang digunakan yaitu uji Kolmogorov-Smirnov. Data yang diuji yaitu data tingkat keluhan kelelahan, keluhan muskuloskeletal dan tingkat produktivitas pada pekerja dengan menggunkan alat pembelah buah pinang sebelum dan sesudah rancangan. Uji normalitas dilakukan pada masing-masing variable. Hasil perhitungan diperoleh bahwa probabilitas pada masing-masing variabel sebelum dan sesudah dilakukan perancangan alat diperoleh lebih besar dari 0,05 ( $p>0,05)$, sehingga data dinyatakan berdistribusi normal.

Selanjutnya dilakukan uji beda. Uji beda yang digunakan dalam penelitian ini adalah uji parametrik dengan uji $\mathrm{t}$ berpasangan karena data yang diambil kurang dari 30 dan secara keseluruhan data berdistribusi normal.

Untuk tingkat kelelahan diukur dengan menggunakan kuesioner kelelahan dengan skala likert sebelum dan sesudah rancangan alat. Hasil perhitungan bahwa untuk tingkat kelelahan diperoleh nilai probabilitas sebesar $0.013(P<0.05)$, sehingga dinyatakan bahwa terdapat penurunan kelelahan secara bermakna antara alat lama dengan alat baru. Beda rerata tingkat keluhan kelelahan antara alat lama dengan alat baru adalah 14,24 atau terjadi penurunan keluhan kelelahan sebesar $24,12 \%$. Berikut grafik perbedaan tingkat kelelahan antara alat lama dan alat baru.

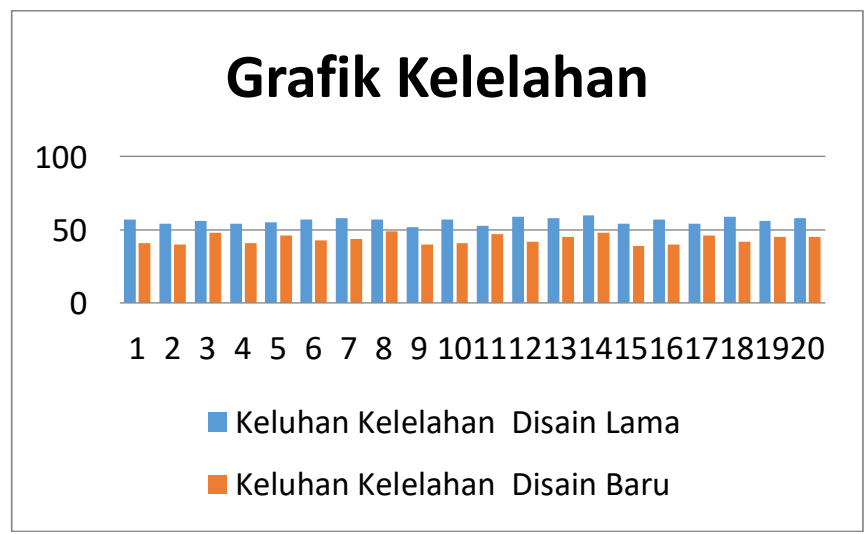

Gambar 6. Perbedaan Keluhan Kelelahan Alat Lama Alat Baru 
Untuk keluhan muskuloskeletal diukur dengan menggunakan kuisioner Nordic Body Map dengan skala Likert yang diisi oleh partisipan untuk mengetahui perbedaan alat lama dan alat baru. Nilai keluhan merupakan jumlah nilai keluhan yang dirasakan oleh partisipan yang terdapat pada kuesioner setelah menggunakan alat lama dan alat baru. Untuk tingkat keluhan muskuloskeletal didapat nilai probabilitas sebesar $0,000(p<0,05)$ sehingga dinyatakan bahwa terdapat penurunan keluhan muskuloskeletal secara bermakna antara alat pembelah buah pinang alat lama dengan alat baru. Beda rerata atara alat pembelah alat lama dengan alat baru adalah sebesar 8,65 atau terjadi penurunan keluhan muskuloskeletal sebesar 15,83\%. Berikut grafik perbedaan keluhan muskuloskeletal yang dirasakan oleh pekerja menggunakan alat lama dan alat baru.

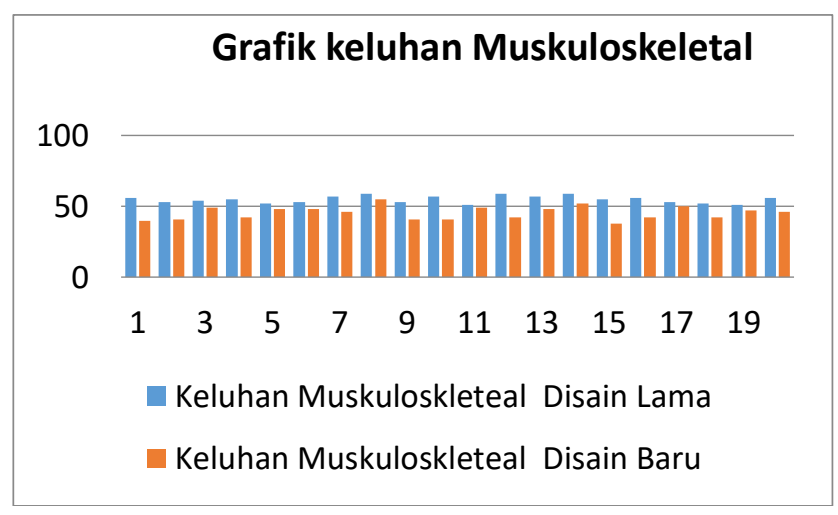

Gambar 7. Perbedaan Keluhan Muskulodkeletal Alat Lama dan Alat Baru

Untuk tingkat produktivitas kerja didapat nilai probabilitas sebesar $0,000(p<0,05)$ sehingga dinyatakan bahwa terdapat peningkatan produktivitas kerja secara bermakna antara alat pembelah buah pinang lama dengan alat baru. Beda rerata antara alat pembelah buah pinang disain lama dengan disain baru adalah 4,16 atau terjadi peningkatan produktivitas sebesar 12,76\%. Perbedaan tingkat produktivitas kerja antar alat pembelah buah pinang lama dengan baru dapat dilihat pada grafik di bawah ini.

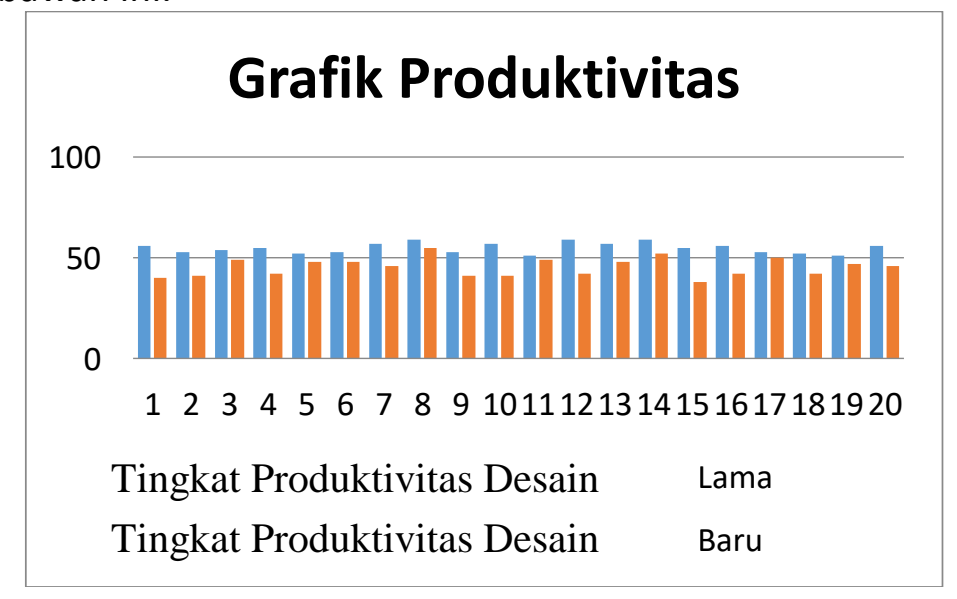

Gambar 8. Perbedaan Tingkat Produktivitas Alat Lama dan Alat Baru 


\section{Kesimpulan}

Alat pembelah buah pinang hasil rancangan mampu meminimalisir tingkat kecelakaan kerja akibat dari adanya perubahan posisi pisau pembelah, kemudian mampu menurunkan keluhan kelelahan dan muskuloskeletal penurunan keluhan kelelahan sebesar 24,12\%, keluhan muskuloskeletal $15,83 \%$ dan terjadi peningkatan produktivitas sebesar $12,76 \%$.

\section{Ucapan Terimakasih}

Program Pengabdian Kepada Masyarakat ini terlaksana atas bantuan dana dari pihak LPPM UIN Suska Riau, demikian juga dengan pihak pimpinan UIN Suska Riau, Khususnya di Prodi Teknik Industri telah banyak mensuport. Untuk itu pada kesempatan ini kami dari tim menyampaikan ucapan terimakasih. Penghargaan dan apresiasi yang setinggi-tingginya juga kami sampaikan kepada kepala Desa Kayu Raja dan stafnya, Bapak Andi Agus, Ahmad, dan Dahli serta seluruh pekerja pinang yang telah terlibat dalam menyukseskan program pengabdian ini.

\section{DAFTAR PUSTAKA}

Anies, 2014, Kedokteran Okupasi Berbagai Penyakit Akibat Kerja dan Upaya Penanggulangan dari Aspek Kedokteran. Yogyakarta: Ar-Ruzz Media.

Anies. 2005. Penyakit Akibat Kerja. Gramedia. Jakarta.

Daryanto, Sutjana dan Muliarti. 2016. Redesain Rakel dan Pemberian Peregangan Aktif Menurunkan Beban Kerja dan Keluhan Muskuloskeletal Serta Meningkatkan Produktivitas Kerja Pekerja Sablon Pada Industri Sablon Surya Bali Di Denpasar. Jurnal Ergonomi Indonesia, Vol. 2, No. 2, 1 Juli-Desember 2016.

Departemen kesehatan RI. Direktorat Bina Kesehatan Kerja, Direktorat Jenderal Bina

Farida Nursholiha. 2009. Hubungan Antara Posisi Duduk dengan Keluhan Subjektif pada Punggung pada Pengrajin Rebana Desa Kali Wadas Kecamatan Bumiayau Kabupaten Brebes. Skripsi. Universitas Negeri Semarang, Semarang.

http//hargabarangterbaru.top. Harga Buah Painang 2017. Dilihat pada tanggal 12 April 2017

Kartana, T. 2010. Faktor-faktor yang Mempengaruhi Keluhan Nyeri Punggung Bawah Pada Kegiatan Mengemudi Tim Ekspedisi PT. Enserval Putera Megatrading Jakarta Tahun 2010. Skripsi. Universitas Islam Negeri Syarif Hidayatullah, Jakarta.

Kesehatan Masyarakat. Strategi Nasional Kesehatan Kerja di Indonesia. Jakarta. 2007;10-11

Kompas.com 2010. Hasiat Buah Pinang, Dilihat pada tanggal 10 Maret 2017. Tersedia di http://Kompas.com

Lingga, G. 2011. Media Relation Officer ILO. Jakarta.

Peraturan Menteri Tenaga Kerja dan Transmigrasi No. Per.01/MEN/1981 tentang Kewajiban Melaporkan Penyakit Akibat Kerja.

Pulat, B. M. 2000. Fundamental of Industrial Ergonomics. USA: Waveland Press Inc.

Santoso, Gempur, 2004. Ergonomi Manusia, Peralatan dan Lingkungan. Jakarta : Prestasi Pustaka Publisher

Sugiyono. 2004. Statistik Untuk Penelitian. CV. Alfa Beta. Bandung.

Suma'mur P.K. 1996. Higiene Perusahaan dan Kesehatan Kerja. Gunung Agung. Jakarta. 
Surya, R. Z, 2012. Perbaikan Sistem Kerja Berbasis Ergonomi Partisipatori Untuk Meningkatkan Kesejahteraan Karyawa, tesis MTI, Universitas Islam Indonesia, Yogyakarta.

Susana, I. G. B. ,2016, -Rancangan Ruang Pengering Berbasis Ergonomi Menurunkan Keluhan Muskuloskeletal Perajin Ikan. Dinamika Teknik Mesin. Volume 6. No. 1

Sutalaksana, I.Z, 2000. Peningkatan Produktivitas Dengan Penerapan Ergonomi. Konvensi K3 2000.di Jakarta 18-20 Januari.

Tarwaka dkk. 2004. Ergonomi Untuk Keselamatan Kesehatan Kerja dan Produktivitas. UNIBA Press. Surakarta.

Tarwaka, et., al, 2004. Ergonomi untuk Keselamatan, Kesehatan Kerja dan Produktivitas. Surakarta: UNIBA PRES.

Undang-undang No. 23 Tahun 1992 tentang Kesehatan, Pasal 23 mengenai Kesehatan Kerja.

Walpole Rodald Raymond H Myers,1995,IImu Peluang dan Statistika Untuk Insinyur dan IImuwan, edisi kedua, penerbit ITB.

Xiang $\mathrm{H}$, Stallones $\mathrm{L}$ dan Keefe TJ. Back pain and agricultural work among farmers: an analysis of the Colorado Farm Family Health and Hazard Surveillance Survey. Jurnal (online): Ind Med 1999; 35: 310-316. http://occmed.oxfordjournals.org. diakses tanggal 14 September 2017. 